\title{
Do food scares explain supplier concentration? An analysis of EU agri-food imports
}

\author{
Mélise Jaud ${ }^{\dagger}$, Olivier Cadot ${ }^{*}$ and Akiko Suwa-Eisenmann ${ }^{\S *}$ \\ ${ }^{\dagger}$ World Bank, Washington, DC, USA; ${ }^{\ddagger}$ University of Lausanne, CEPR, \\ CEPREMAP and FERDI, Switzerland; ${ }^{\S}$ Paris School of Economics- \\ Institut National de la Recherche Agronomique, France
}

Received May 2011; final version accepted May 2012

Review coordinated by Thomas Heckelei

\begin{abstract}
We investigate how rising sanitary risk of agri-food products affects the geographical concentration of European Union (EU) imports at the product level. We first estimate a product-specific measure of sanitary risk based on the count of food alerts at EU borders. Then we regress the evolution of geographical concentration indices on our measure of product risk and year. We find that product sanitary risk indeed affected the EU import pattern. Overall, the EU diversified its import sources, but with diversification at the extensive margin and concentration at the intensive margin. This pattern is stronger for risky products, leading to a two-tier system.
\end{abstract}

Keywords: Rapid Alert System for Food and Feed, European Union, import concentration, Sanitary Risk Index, food safety, agricultural trade

JEL classification: F14, Q17, Q18

\section{Introduction}

After a series of highly publicised food scares (such as bovine spongiform encephalopathy or dioxin-contaminated chickens), public-health concerns have started to loom large in the buying policies of European Union (EU) distributors. These concerns have the potential to affect the evolution of EU foodstuff imports and therefore the access that developing countries enjoy on EU markets. This is the case for the poorest countries that find it most difficult to comply with stringent sanitary standards (Maskus, Otsuki and Wilson, 2005; Garcia-Martinez, Poole and Skinner, 2006). 
The evolution of EU foodstuff import pattern over time results from a tradeoff between diversification and concentration forces. First, several elements may drive geographical diversification. The importer's taste for variety or a desire to limit monopoly positions would lead to a larger number of suppliers to import from. Also, as the access to the EU market becomes easier - decrease in transport costs and traditional trade barriers such as tariffs - more countries are able to sell abroad. Alternatively, if productivity rises exogenously in a pool of potential suppliers with heterogeneous productivity levels, the number of suppliers for a given product will enlarge (Helpman, Melitz and Rubinstein, 2008). In practice, EU demand of agri-food products has recently moved from tropical goods (such as coffee or cocoa) more to temperate zone goods (such as fruits, vegetables and fish) which are potentially produced by a larger number of developing countries. Second, concentration forces arise from the oligopolistic trend in the agro-food industry (the rise of 'supermarkets') and its procurement system (Reardon and Timmer, 2007). In the case of goods with a particular safety concern for the importer (Henson and Jaffee, 2004; Jaffee et al., 2005; Czubala, Shepherd and Wilson, 2007) the need to source from reliable producers accentuates this trend. Importantly, the actors of this trade-off between diversification and concentration forces are evolving over time, as new exporters progressively build up their reputation of quality for their product and because incumbent exporters are never completely immune to food safety crisis.

This paper examines the link between the risk of food products and recent changes in the EU import pattern. Specifically, we investigate how the sanitary risk of agri-food products affects the geographical concentration of EU imports at the product level. We use a unique database that reports all agrifood shipments that have suffered rejection at the EU border due to food safety reasons. ${ }^{1}$ The incidence of food alerts is fairly heterogeneous across exporting countries and might reflect exporters' past performance or hidden protectionism against them. Regressing concentration indices on a raw count of alerts at the product level would say nothing without controlling for other factors. Thus, we rely on a two-step procedure where we first estimate a product-specific sanitary risk, based on food alerts controlling for confounding factors; then we regress, in a second step, the evolution of geographical concentration on our measure of product risk.

We find evidence that product sanitary risk has indeed affected the EU import pattern. Overall, there is a slight diversification of import sources over time. This overall trend hides diversification at the extensive margin and concentration at the intensive margin, the more so for risky products. On the one hand, most of EU agri-food imports come from a few sources. On the other hand, additional new countries enter the EU market. Yet, they enter on a smaller scale than before. As a result, EU foodstuff imports gradually

1 Baylis et al. (2010) rely on the RASFF database to analyse the trade diversion and deflection effects of EU food import refusals in the case of fishery products. 
evolve towards a two-tier distribution with a small number of dominant suppliers and a growing fringe of marginal ones.

Our work relates to two distinct lines of research. First, this paper contributes to the literature on trade patterns along the development process. Following the seminal work of Imbs and Wacziarg (2003) on production and employment, most papers have considered diversification at the product level. Klinger and Lederman (2004), and Cadot, Carrère and Strauss-Kahn (2011) document a similar hump-shaped pattern for export diversification. As to geographical diversification, micro-studies suggest a role for proximity and experience gained in the destination markets. A country starts exporting to one market and gradually expands to the neighbouring countries (Evenett and Venables, 2002). This stylised fact finds further support in Eaton et al. (2008), a detailed study of Colombian exports.

Second, this paper contributes to the literature on sanitary and phytosanitary (SPS) standards as potential barriers to trade. Initially, SPS standards are not meant to discriminate against imported goods. However, in practice, exporters in poor countries may be priced out of the EU market. Complying with standards is costly, not only because of fixed costs of implementation at the outset but also due to recurring costs associated with sustained traceability, certification or quality inspection. In addition, EU standards - often more specific and restrictive than multilateral Codex ones - are suspected of going beyond the requirements dictated by mere sanitary concerns. An important set of research has focused on the quantitative assessment of the trade effects of standards essentially by sticking standards as explanatory variables in gravity equations (Otsuki, Wilson and Sewadeh, 2001; Moenius, 2006). Results are mixed. Some country-specific standards tend to reduce trade, others promote it (Fontagné, Mimouni and Pasteels, 2005). Crucially, the impact of importing country standards is negatively correlated with the level of income of the exporting country (Disdier, Fontagné and Mimouni, 2008). Another set of works, largely based on detailed case studies, provides further nuance. Gravity model findings tend to represent short-run, average effects and do not account for the medium-term catalysing role product standards may play in the promotion of quality upgrading in developing countries (Diaz Rios and Jaffee, 2008).

We differentiate ourselves from the existing literature in three important ways. First, we adopt an ex post approach and consider effective product sanitary risk based on food alerts at the EU borders. Our ex post approach complements the previously cited studies that, in contrast, rely on what could be considered de jure measures of sanitary risk. Second, contrary to previous papers, we take the view point of the importer (EU-12) and not the exporter. Finally, we shift focus from gravity modelling to an analysis of the geographical concentration of EU agri-food imports based on Theil's entropy index. The index separability property enables us to decompose the overall geographical concentration into variations at the extensive and intensive margins.

The rest of the paper is structured as follows: the next section describes the data, in particular the EU 'food alerts' database. Section 3 details our 
empirical strategy, including the two-step methodology developed for our analysis. Section 4 reports the main empirical results, while Section 5 concludes.

\section{Data}

\subsection{The food alerts data}

We use EUROSTAT's Rapid Alert System for Food and Feed (RASFF) for EU12 countries. ${ }^{2}$ The RASFF is a system of notification and information exchange on emergency sanitary measures taken at the border by EU member states, in place since $1979 .{ }^{3}$ The database records all notifications $(19,000)$ between 2001 and 2008 with the identity of the reporting importing EU member state, exporting country, product, hazard, type of notification and type of measure.

There are two limitations to the data. The first is a selection bias issue. Indeed, only products exported to the EU and for which SPS regulations are in place in the EU may be inspected and thus rejected. The second is that alerts do not result from a random sampling of imports. On the contrary, they reflect the concern of food hygiene control services with respect to certain growers or shippers. Despite these caveats, the RASFF database provides reliable and best available information on the effective problems related to food imports safety.

The database contains complete information regarding products, though in verbal form. We painstakingly coded all products into CN8 categories over the period 2001-2005 (8,895 observations) and matched them with trade data. ${ }^{4}$ The number of notifications sharply rose from 500 in 2001 to 2,000 in 2005, although somewhat decelerating after 2003. EU member states are heterogeneous in terms of the frequency of notifications (Figure 1, panel a). Germany, Italy and Spain are the top notifying countries, with Ireland at the other end. This may reflect differing agri-food import structures or controls procedures among EU member states. In the following econometric analysis, we aggregate notifications across all EU members and years to smooth out these variations. There is also considerable heterogeneity among products (panel b). Fruit and nuts, fish and coffee rank highest in terms of reported notifications. In terms of hazards, contamination by mycotoxins (mainly aflatoxin) is the main cause of notifications for agricultural products and affects mostly dried fruits and nuts (panel c). The second cause is contamination by residues

2 France, Belgium, Luxembourg, the Netherlands, Germany, Italy, Ireland, United Kingdom, Denmark, Greece, Portugal and Spain. We use this restrictive definition for consistency of time series, as EUROSTAT does not provide data on Member States before their accession.

3 The data set does not include information on intra-EU trade, which is subject to mutual recognition of norms. The safety of intra-EU food trade is supervised by the Standing Committee on the Food Chain and Animal Health or, in case of emergency, the Commission itself. Alerts specific to animal products traded within the EU are reported in the TRACES (TRAde Control and Expert System) database.

4 For a more complete description of the data set, see Jaud (2011). 

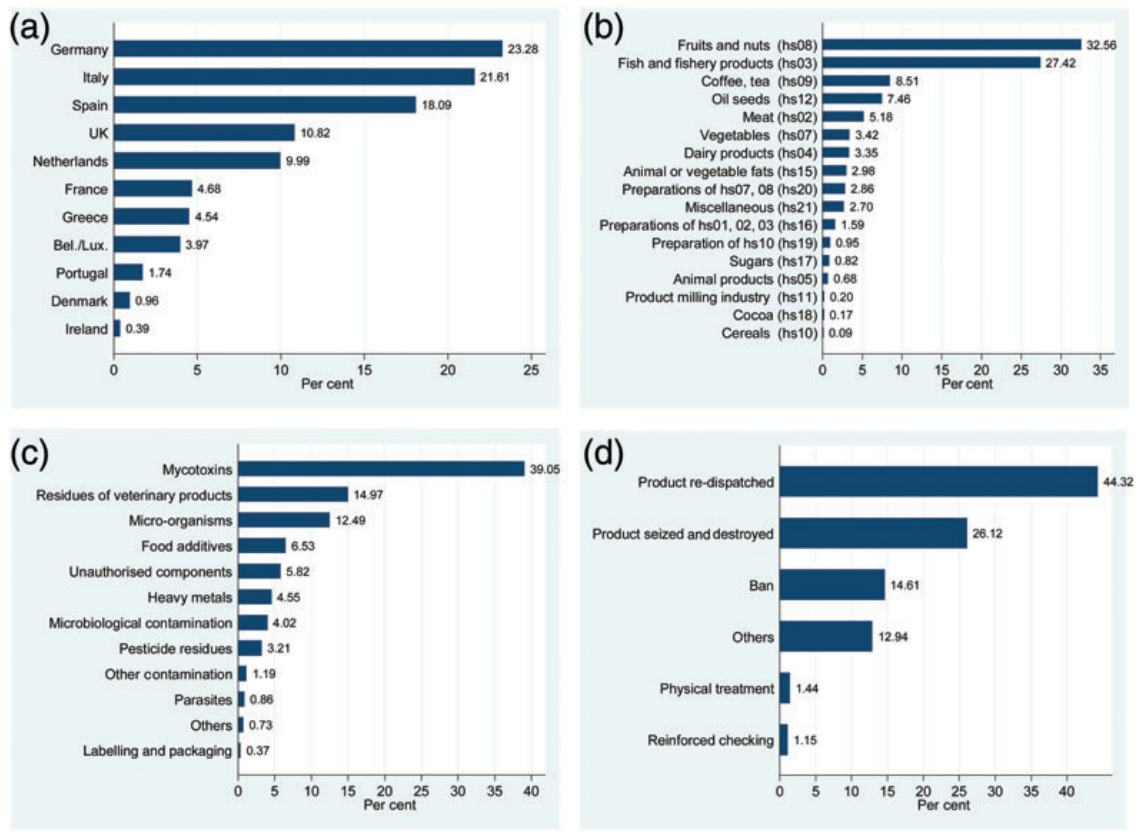

Fig. 1. The food alert database, 2001-2005. (a) Notification by importing country. (b) Notifications per $\mathrm{CN} 2$ sector. (c) Notifications per hazard category. (d) Actions taken after notification.

Note: All statistics are computed as average over the period 2001-2005.

of veterinary medicinal products, typically on sensitive products such as fish and shrimps. Pathogenic micro-organisms concern especially cereals, and pesticide residues affect fruit and vegetables. In terms of the action taken after notification, over 85 per cent of notified shipments are stopped at the border and are re-dispatched to extra-EU destinations, destroyed or banned (panel d).

Figure 2 shows a scatter plot of exporters' total number of notifications between 2001 and 2005 against their level of development in 2001, both taken in logs. The size of the circles and diamonds is proportional to the country's share in EU food imports in 2005. China, Turkey and Brazil are most affected by SPS notifications, but they are also among EU's largest suppliers. Countries like Canada, Norway, New Zealand or the USA are large exporters but subject to relatively few notifications.

At the other end of the spectrum, Iran and Vietnam suffer a disproportionate number of notifications given their relatively lower import shares. This dispersion suggests that important country-specific characteristics, on top of sales volumes, affect the probability of getting a notification. These characteristics include obviously the product composition of exports, as well as unobserved characteristics of national production systems. 


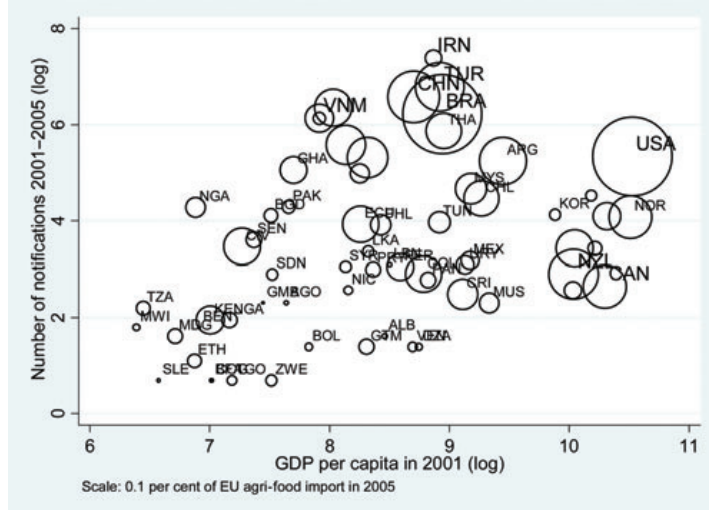

Fig. 2. Main exporters concerned by SPS notifications. Note: Simple averages at the product (CN8) level.

\subsection{European agri-food imports}

We use EUROSTAT agri-food import data for EU-12 from 147 exporting countries, including 122 developing countries, between 1988 and 2005, at the CN8 level. Agri-food products, excluding beverages and animal feed, are in chapters $1-21$ of the $\mathrm{CN}$ system, which represent 3,073 potential export lines. We account for reclassifications due to $\mathrm{CN}$ harmonisations in 1988, 1996 and 2002 and build a consistent database using the initial nomenclature.

EU agri-food imports has evolved between 1988 and 2005. The share of developing countries, already dominant at 66 per cent in 1988, grew even more, reaching 70 per cent in 2001 and 75 per cent in 2005. Interestingly, this rise is not attributable to traditional tropical products (such as coffee, cocoa and sugar) which, as a share of imports from developing countries, shrank from 23.9 to 15.4 per cent over the sample period. Rather, it is due to fruit, vegetables and fisheries products, whose share in EU agri-food imports from developing countries rose from 21.6 to 29.6 per cent. This is a noticeable evolution as fisheries and horticulture products are highly sensitive to SPS issues.

Interestingly, the EU sources its agri-food products from a small number of partners; on average, 12 per cent of transactions over 1988-2005 come from a single supplier country - there may be several supplying firms per exporting country. This high degree of market concentration may be partially driven by the presence of bilateral tariff quotas.

Concentration varies across sectors. Dairy products and meat are extremely concentrated with, respectively, 39 and 35 per cent of transactions involving a unique partner. Oppositely, the vegetable plaiting material or coffee and tea sectors exhibit no single-partner transactions. The milling industry and the agro-food industry preparing fats or food based on meat, fish or vegetables 
stand in between, with a share of single-supplier transactions between 11 and 20 per cent, while fruit and vegetables, cocoa and fishery sectors have a singlesupplier share below 10 per cent.

\section{Empirical strategy}

We now investigate how the sanitary risk of agri-food products affect the geographical concentration of EU imports at the product level.

\subsection{Concentration indices}

We use the Theil entropy index (Theil, 1972) as an indicator of concentration because it is decomposable and adequate in capturing the action at both ends of the distribution. ${ }^{5}$

Omitting the time indices, for good $k$, the Theil index is given by

$$
T_{k}=\frac{1}{n_{k}} \sum_{c=1}^{n_{k}} \frac{x_{k}^{c}}{\mu_{k}} \ln \left(\frac{x_{k}^{c}}{\mu_{k}}\right),
$$

where $\mu_{k}=1 / n_{k} \sum_{c=1}^{n_{k}} x_{k}^{c}$ is the average value of import for good $k$ from origin country $c$ and $n_{k}$ is the total number of countries exporting good $k$.

The Theil index depends on the definition of $n_{k}$, the number of 'potential exporters', defined as the set of all countries having exported good $k$ to some destination in the world (not necessarily EU countries) at least two years in a row over the sample period. We impose the requirement of two consecutive years of exports in order to ensure that the exporter is a successful one. Indeed, Besedes and Prusa (2006) show that two years is the median duration of export spells. This definition of potential exporters has the advantage of being time-invariant. ${ }^{6}$

\subsection{Intensive versus extensive margins}

We use the additive decomposability property of the Theil index to get a first cut at the respective roles of the geographical intensive and extensive margins in the overall concentration trends. In each year, we decompose our sample of EU suppliers into two groups. Group $1, G_{1}$, is composed of active suppliers, numbering $n_{k t}^{1}=n_{k t}^{\mathrm{EU}}$, and group $0, G_{0}$, is made of potential but inactive ones, numbering $n_{k t}^{0}=n_{k}-n_{k t}^{\mathrm{EU}}$. The Theil indices in each group are $T_{k t}^{0}, T_{k t}^{1}$.

5 We have also used alternative concentration indices, Gini, Herfindahl and the largest import share, that put emphasis on different segments of the distribution, to test for the robustness of our results. Results were similar and are available upon request.

6 Regression results are robust to alternative definitions of the number of potential exporters (results not reported here). 
The between-group component of Theil index is given by

$$
T_{k t}^{B}=\sum_{j=0,1} \frac{n_{k t}^{j}}{n_{k}} \frac{\mu_{k t}^{j}}{\mu_{k t}} \ln \left(\frac{\mu_{k t}^{j}}{\mu_{k t}}\right) .
$$

It is a weighted average of terms involving only group means (relative to the population mean). After a little algebra, it follows that:

$$
T_{k t}^{B}=\ln \left(\frac{n_{k}}{n_{k t}^{\mathrm{EU}}}\right) .
$$

As $n_{k}$ is time invariant,

$$
\Delta T_{k t}^{B}=T_{k t}^{B}-T_{k t-1}^{B}=-\Delta \ln n_{k t}^{\mathrm{EU}} .
$$

That is, changes in the between-group components of Theil index trace exactly the percentage changes in the extensive margin defined as the number of active suppliers.

The within-group Theil index is defined as

$$
T_{k t}^{W}=\sum_{j=0,1} \frac{n_{k t}^{j}}{n_{k}} \frac{\mu_{k t}^{j}}{\mu_{k t}} T_{k t}^{j} .
$$

As Theil index is zero when all countries have equal shares, $T_{k t}^{0}=0$. As for group 1,

$$
T_{k t}^{1}=\frac{1}{n_{k t}^{1}} \sum_{c \in G_{1}} \frac{x_{k t}^{c}}{\mu_{k t}^{1}} \ln \left(\frac{x_{k t}^{c}}{\mu_{k t}^{1}}\right)
$$

And $T_{k t}^{W}$ reduces to

$$
T_{k t}^{W}=\frac{n_{k t}^{\mathrm{EU}}}{n_{k t}} \frac{\mu_{k t}^{\mathrm{EU}}}{\mu_{k t}} T_{k t}^{1}
$$

where $\mu_{k t}^{\mathrm{EU}}=\mu_{k t}^{1}$. That is, the within component of Theil index is equal to its group-1 sub-index (concentration among active suppliers). Hence, given our partition of suppliers, the between-group and within-group components of Theil index map directly into the extensive and intensive margins.

\subsection{Product sanitary risk and concentration}

In order to examine the impact of sanitary risk on EU agro-food imports pattern, we rely on a two-step procedure where we estimate first a measure of sanitary risk based on food alerts. 


\subsubsection{Step 1}

For a product $k$ and an exporter $c$, the dependent variable is the combined count of notifications from all 12 EU member states between 2001 and 2005. Our variable of interest is the coefficient on the product dummy, $\delta_{k}$, in the following cross-section regression:

$$
\text { Alert }_{c k}=f\left(\alpha \text { Imp_share }_{c k}^{\mathrm{EU}}+\beta \text { Controls }_{k}+\delta_{c}+\delta_{k}+\varepsilon_{c k}\right),
$$

where $\varepsilon_{c k}$ is an error term. ${ }^{7}$ Because the number of notifications is a count, with over-dispersion and a large proportion of zeros, estimation is made with a negative binomial. We include exporter $c$ share in EU imports of product $k$ in 2000 (one year before the sample start) (Imp_share ${ }_{c k}^{\mathrm{EU}}$ ). Indeed, a product imported overwhelmingly from a country with weak quality standards would appear as risky, even though other exporters might have managed to make the product safe. In addition, the incidence of alerts is likely to be correlated with the frequency of inspections which might be correlated to protectionism. Hence, we include the ad valorem equivalent of the EU's MFN tariff on product $k$ in $2005\left(\operatorname{tariff}_{k}\right)$ and dummy variables indicating whether product $k$ is affected by a quota during the sample period (quota ${ }_{k}$ ), whether product $k$ has been the object of a dispute at the WTO involving the EU and any other country (dispute ${ }_{k}$ ) and whether exporter $c$ has been affected by a ban on product $k$ during the sample period $\left(\operatorname{ban}_{c k}\right) .{ }^{8}$ Indeed, a ban could result in less notifications just because there will be no flow at all. We also control for the initial value of EU imports of product $k$ in 2000, as products imported in large volumes are likely to be inspected, and therefore fail inspections, more often than others. ${ }^{9}$

The regression also includes product and exporter fixed effects. The latter controls for all supplier's characteristics that may affect the quality of the product, such as the overall level of economic development. As a consequence, the coefficient of the product dummy captures the part of food alerts that is due to the product itself, net of exporters' characteristics and of other factors that may affect the probability of rejection. It is what we label the estimated product Sanitary Risk Index (SRI). ${ }^{10}$

7 All observations are pooled in the step- 1 regression. Pooling attenuates the heterogeneity in the number of notifications across importers. But this choice entails some drawbacks: it rules out the possibility to control for supplier-product fixed effects; it might also exacerbate the potential multi-collinearity between protection measures and the estimated sanitary risk index.

8 The tariff is the applied ad valorem tariff, including specific duties, preferential agreements and excluding quotas, computed on TARIC, provided by J. Gallezot (2003).

9 We rely on STATA 'exposure' option for count models. This command is equivalent to including the initial volume of imports as a regressor with a coefficient constrained to be equal to 1 .

10 When estimated coefficients were not significant at the 10 per cent level, they were set equal to 0 . This is the case for 39 per cent of the HS-8 product lines. We also normalise the coefficients so as to obtain non-negative values. 


\subsubsection{Step 2}

Estimated SRI, $\hat{\delta}_{k}$, are used as explanatory variables in a panel regression of concentration indices:

$$
C_{k t}=a+b \text { Controls }_{k}+\gamma \hat{\delta}_{k}+\eta \hat{\delta}_{k} * \delta_{t}+\delta_{t}+\delta_{s}+v_{k t},
$$

where $C_{k t}$ is a measure of concentration (overall Theil index, its within- and between-group components or the number of active suppliers) for good $k$ in year $t$. Control variables are the same as in the first step. Time effects enter the equation both linearly and interacted with the SRI, so as to see whether concentration has evolved differently for risky products. Sector-specific fixed effects (at the CN-4 level) control for time-invariant characteristics such as supply chains and vertical integration.

In the second step, the dependent variable is defined at the product level, with no reference to the specificity of the exporter, which was dealt with in the previous step. If one exporter was consistently 'bad', that would be indeed taken into account in step 1. However, if all the 'bad' exporters were exporting exactly the same products, spurious correlation could occur, which would result in over-estimating the impact of risk on concentration. This case is though most unlikely at the very detailed CN-8 level. ${ }^{11}$

\section{Empirical results}

\subsection{Descriptive statistics}

Figure 3 replaces the sample period in a broader perspective and shows the evolution of the geographical concentration indices between 1988 and 2005 . The overall Theil index shows a downward trend: geographical diversification has occurred over time. It is paralleled by a similar downward trend of the between-component of the Theil index, along with a rising number of suppliers suggesting diversification at the extensive margin. However, the within-group component of the Theil index shows an upward trend, indicating a rising concentration among active EU's suppliers. These trends are accentuated after 2000 .

Table 1 provides summary statistics of the main variables used in our analysis. The average number of potential suppliers is high (78), in contrast with the average number of actual suppliers (12). Concentration indices are very high, and this is consistent with our earlier observation that the distribution of the number of active suppliers is highly skewed. It could also be partly due to the very detailed level of disaggregation. The last line of Table 1 presents the estimated SRI, resulting from step-1 regression. It ranges between 0 and 12.2 , with a mean at 0.76 .

Table 2 provides a list of the sectors associated with the highest sanitary risk. It stresses the relevance of our first-step regression. Sectors estimated

11 As the product dummies used in the second-step regression are generated regressors, standard errors are computed with a bootstrap. 

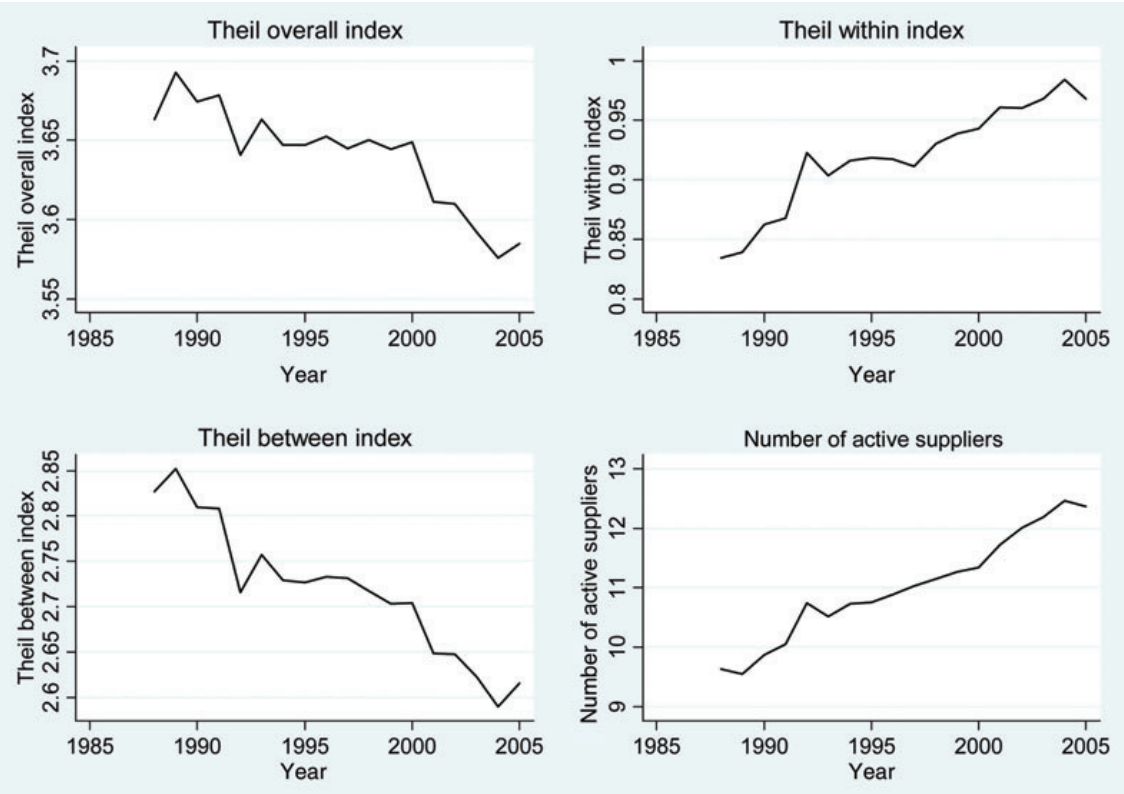

Fig. 3. Evolution of geographical concentration, 1988-2005.

Note: All statistics are computed as simple averages at the product (CN8) level.

Table 1. Summary statistics, 2001-2005

\begin{tabular}{lcrccr}
\hline Variable & Observations & Mean & Std Dev. & Min & Max \\
\hline Theil overall, $T_{k t}$ & 8,598 & 3.30 & 0.71 & 0.66 & 4.99 \\
Theil within, $T_{k t}^{W}$ & 8,608 & 0.96 & 0.67 & 0 & 3.27 \\
Theil between, $T_{k t}^{B}$ & 8,608 & 2.34 & 1.06 & -1.39 & 4.99 \\
Number of active suppliers, $n_{k t}^{\mathrm{EU}}$ & 8,608 & 12.01 & 12.52 & 1 & 96.00 \\
Number of potential suppliers, $n_{k}$ & 8,608 & 78.56 & 30.09 & 10.00 & 147.00 \\
Sanitary Risk Index, SRI $_{k}$ & 8,608 & 0.76 & 1.99 & 0 & 12.21 \\
\hline
\end{tabular}

with the highest sanitary risk are not necessarily those with the highest number of alerts. ${ }^{12}$ The case of edible fruit and nuts is a striking example. Most of the 3,210 alerts in this sector are attributable to aflatoxin-contaminated Iranian pistachios. After controlling for the latter, the sector ranks only sixth in terms of sanitary risk, while fishery products and spices emerge as the riskiest.

Out of a total of 2,146 CN8 products, first-step regression results yielded 373 estimated product coefficients. No product chapter stands out as having

12 The correlation between the SRI and the average number of alerts between 2001 and 2005 is equal to 0.32 . 
Table 2. SRI at the $\mathrm{CN} 2$ level

\begin{tabular}{|c|c|c|c|c|}
\hline Sector & $\begin{array}{l}\text { Number } \\
\text { of risky } \\
\text { products }\end{array}$ & $\mathrm{SRI}^{\mathrm{a}}$ & $\begin{array}{l}\text { Number } \\
\text { of alerts } \\
2001- \\
2005\end{array}$ & $\begin{array}{l}\text { Most frequent } \\
\text { cause for } \\
\text { rejection }\end{array}$ \\
\hline Coffee, tea, mate, spices & 38 & 2.07 & 934 & $\begin{array}{l}\text { Composition, } \\
\text { mycotoxins }\end{array}$ \\
\hline Preparations of meat and fish & 32 & 1.29 & 309 & Veterinary drugs residues \\
\hline Oil seeds and oleaginous fruits & 25 & 1.04 & 1,491 & Mycotoxins \\
\hline Fish, crustaceans and molluscs & 108 & 0.95 & 2,641 & Veterinary drugs residues \\
\hline Miscellaneous edible preps & 7 & 0.85 & 185 & Food additives \\
\hline Edible fruit and nuts & 53 & 0.71 & 3,210 & Mycotoxins \\
\hline Edible vegetables & 27 & 0.65 & 441 & Pesticide residues \\
\hline Cocoa and cocoa prep. & 4 & 0.57 & 20 & Allergens \\
\hline Prepared vegetable, fruit, nuts & 44 & 0.54 & 677 & Mycotoxins \\
\hline Sugar & 5 & 0.49 & 221 & $\begin{array}{c}\text { Food additives } \\
\text { mycotoxins }\end{array}$ \\
\hline Products of animal origin & 3 & 0.48 & 40 & Veterinary drugs residues \\
\hline Meat and edible meat offal & 17 & 0.24 & 498 & Pathogens \\
\hline Animal or vegetable fats & 7 & 0.18 & 247 & Composition \\
\hline Preparations of cereals & 2 & 0.16 & 167 & Radiation \\
\hline Dairy produce & 0 & 0.03 & 367 & Veterinary drugs residues \\
\hline Live animals & 0 & 0 & 1 & Heavy metals \\
\hline Live trees and other plants & 0 & 0 & 0 & - \\
\hline Cereals & 0 & 0 & 158 & GMO/mycotoxins \\
\hline Milling industry products & 0 & 0 & 36 & Food additives \\
\hline Resins, gums & 0 & 0 & 1 & Food additives \\
\hline Vegetable plaiting materials & 1 & 0 & 1 & Labelling incorrect \\
\hline
\end{tabular}

Risky products are products with a positive and significant SRI.

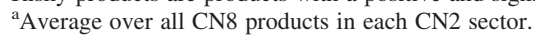

particularly high risk levels, except for fisheries products, with mussels as an unsurprising outlier (Figure 4). Remarkably, traditional tropical products such as coffee and cocoa, whose share in EU foodstuff imports is declining, are among the safest products.

Our ex post approach, based on effective food alerts, complements previous studies that consider the effect of the existence of public legal standards (without indication on how they are actually implemented). A widely used measure of the latter is the number of notifications of SPS measures made to the WTO. The correlation between the number of public SPS notifications to the WTO (provided in Disdier, Fontagné and Mimouni, 2008) and the SRI is low, at -0.05 . This may partly be explained by the fact that the number of notifications is computed at the HS6 level, while our measure of risk is at the HS8 level. In addition, many products have at least one notification, while few products have a positive SRI, once controlled for exporting country's characteristic and the endogeneity of inspections. 


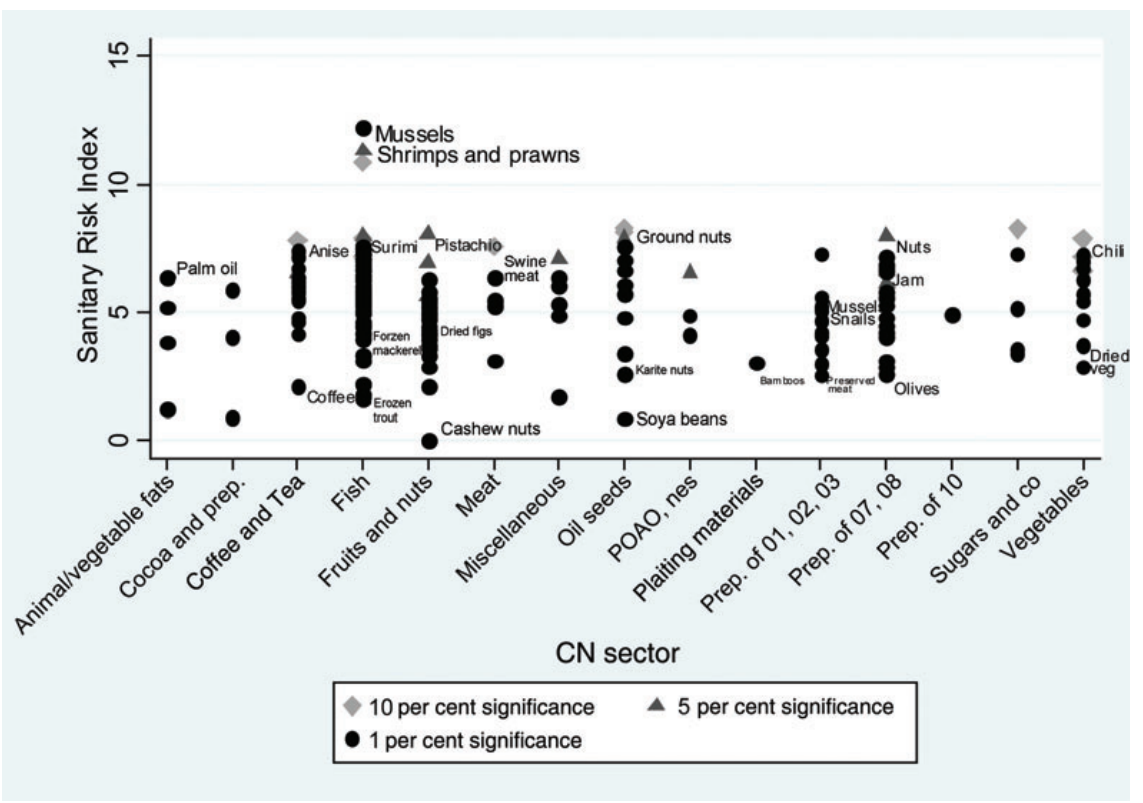

Fig. 4. Distribution of significant point estimates on product dummies

\subsection{Product risk and geographical concentration}

We now turn to the relationship between public-health concerns and the concentration of EU suppliers (Table 3). The dependent variables are, respectively, the four indices of concentration shown in Figure 3. They are regressed on the product sanitary risk and its interaction with a time trend. All regressions are estimated using OLS and include a set of controls with time and sector (CN4) fixed effects. ${ }^{13}$

The coefficients of the product sanitary risk are highly significant and negative: product risk has a negative impact on agro-food import concentration. This overall trend hides two diverging evolutions: at the intensive margin, concentration is higher for riskier products (column 2); at the extensive margin, concentration is lower for those risky products (column 3) and the number of suppliers is higher (column 4). That is, the higher the risk of the product imported, the larger the share of the top suppliers - the intensive margin - and the larger the number of suppliers of that product on the EU market. ${ }^{14}$ Results also suggest that the presence of a quota negatively

13 We run equation (6) in cross-sections, dropping the interaction term. Results remained qualitatively the same and are available upon request.

14 Regressions on SRI alone give a coefficient of 0.073 for the within Theil index and of 2.019 for the number of suppliers. Thus, a 1 per cent increase in the level of the SRI results in a 5.8 per cent $(=0.073 \times 0.76 / 0.96)$ increase in the level of concentration among active suppliers and a 12.7 per cent $(=2.019 \times 0.76 / 12)$ increase in the number of suppliers to the EU. 
Table 3. Sanitary risk and EU import concentration, 2001-2005

\begin{tabular}{|c|c|c|c|c|}
\hline & $\begin{array}{l}\text { (1) } \\
\text { Theil overall }\end{array}$ & $\begin{array}{l}\text { (2) } \\
\text { Theil within }\end{array}$ & $\begin{array}{l}\text { (3) } \\
\text { Theil between }\end{array}$ & $\begin{array}{l}\text { (4) } \\
\text { Number of active suppliers }\end{array}$ \\
\hline sanitary_risk $_{k}$ & $-0.077 * * *(0.010)$ & $0.025 * *(-0.010)$ & $-0.101 * * *(-0.013)$ & $1.255^{* * *}(-0.261)$ \\
\hline sanitary_risk $_{k} \times$ time & $0.017(0.012)$ & $0.086 * * *(-0.012)$ & $-0.0731 * * *(-0.014)$ & $1.358 * * *(-0.296)$ \\
\hline quota $_{k}$ & $0.218 * * *(0.052)$ & $-0.230 * * *(-0.057)$ & $0.447 * * *(-0.082)$ & $-3.151 * * *(-0.878)$ \\
\hline $\operatorname{tariff}{ }_{k}$ & $-0.0007(0.001)$ & $0.0002(-0.001)$ & $-0.0009(-0.001)$ & $-0.010(-0.009)$ \\
\hline $\operatorname{ban}_{k}$ & $0.050(0.150)$ & $-0.025(-0.135)$ & $0.077(-0.201)$ & $-2.216(-2.292)$ \\
\hline dispute $_{k}$ & $-1.264 * * *(0.236)$ & $-0.193(-0.151)$ & $-1.074 * * *(-0.352)$ & $2.301(-6.643)$ \\
\hline Constant & $4.421 * * *(0.149)$ & $1.101 * * *(-0.099)$ & $3.318 * * *(-0.222)$ & $10.145^{* *}(-4.092)$ \\
\hline Observations & 8,602 & 8,608 & 8,608 & 8,608 \\
\hline$R^{2}$ & 0.337 & 0.398 & 0.469 & 0.434 \\
\hline
\end{tabular}

OLS with sector (CN4) and time effects. Bootstrapped standard errors are in parentheses.

* Statistical significance at the 10 per cent level.

** Statistical significance at the 5 per cent level

$* * *$ Statistical significance at the 1 per cent level. 

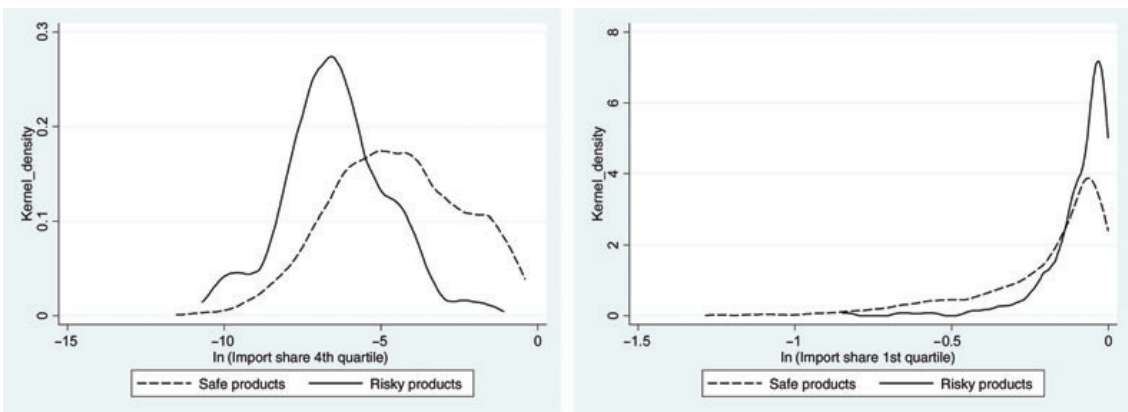

Fig. 5. Import share distribution for risky and safe products, 2005. (a) Smallest exporters, last quartile. (b) Biggest exporters, first quartile.

affects both the dominant position of top suppliers and the number of suppliers. ${ }^{15}$

Figure 5 confirms the rising polarisation between the bottom and the top of the distribution of exporters for risky products. Panels (a) and (b) show the first and last quartile import share distribution in 2005 for risky versus safe products. Risky products are, as before, defined as products with a positive and significant risk coefficient. For the smallest partners, the curve for risky products shifts to the left compared with the curve for safe products, while for the top exporters, the two curves almost overlap. A regression of equation (6) using the import share of the top and the bottom quartile of suppliers as alternative measures of concentration suggests that the import share of the top quartile of suppliers increases with the SRI, while the share of the smallest suppliers decreases with the risk of the products. ${ }^{16}$

All in all, our results provide robust evidence that the distribution of EU suppliers is affected by the level of product sanitary risk. For the riskiest products, we observe few dominant suppliers with a growing fringe of small-scale suppliers.

That said, an interesting follow-up question is whether the new entrants into the EU are also small in world trade. To answer this question and characterise better those small-scale suppliers, we adapt Hummels and Klenow (2005) definition of the (product-wise) extensive margin to a geographical setting, which is written as

$$
\mathrm{EM}_{k}=\frac{\sum_{c \in S_{k}} M_{k}^{c, W}}{\sum_{c} M_{k}^{c, W}},
$$

15 We run equation (6) dropping all products with quotas (25 per cent of observations). Coefficients on the product sanitary risk and the interaction term are of similar level of magnitude and significance, suggesting that the presence of quotas is adequately controlled for in step 1 (results available upon request).

16 Results available upon request. 
with $S_{k}$ being the set of EU active suppliers and $c$ the country. The geographical extensive margin accounts for the importance of EU suppliers' exports in world trade: if the EU imports wheat from the USA and Australia, and rice from Niger and the Mali, both products are sourced from two countries, but the USA and Australia are much larger in wheat trade than are Niger and Mali in rice trade; hence, EM will be higher for wheat than for rice. When regressed over a year dummy, no trend is apparent. This suggests that despite the growing number of EU partners, newcomers into EU supply chains are so small in world trade that they make no difference in the extensive margin. Thus, inequality is rising among EU suppliers, not because large suppliers acquire increasingly dominant positions, but rather because small suppliers, that are also small players in world trade, keep coming in as new exporters to the EU.

A possible explanation for the fact that entrants begin small-scale in the presence of risk is that they are being tested. The explanation put forward for such a pattern is a search for 'food safety' from the buyer, with sellers building up reputations (Jaud, 2010). Alternatively, exporters would want to 'try the market' small-scale before taking big risks (Rauch and Watson, 2003). There may be other mechanisms as well that could contribute to this pattern. First, our results may be capturing the increasing vertical integration of global food supply chains, along with the rise in foreign investment both in food processing and retailing sectors and the dominance of large multinational food companies. Second, the concentration at the intensive margin creates larger rents that may in turn attract smaller exporters - this explanation, however, would suppose neither barriers to entry, nor sunk costs. We leave these questions for future research.

\section{Concluding remarks}

This article establishes a stylised fact on EU import concentration in agri-food products and makes a link between this import pattern and rising public-health concerns in the EU food policy.

While previous empirical works have focused on a de jure definition of standards or their ex ante impact on trade flows, this article is, to our knowledge, the first to assess their ex post and effective impact. Using for the first time a data set on food alerts that provide information on the implementation of SPS standards by EU importing countries, this article contributes to the empirical debate on the evolution of geographical concentration of EU agri-food imports across time. The empirical results are clear. EU foodstuff imports over the period 1988-2005 have gradually evolved towards a two-tier distribution with a small number of dominant suppliers and a growing fringe of marginal ones. European importers tend to buy their agri-food products from an increasingly large portfolio of suppliers, but orders are concentrated on a fewer number of reliable suppliers. This evolution is more marked for products that entail a sanitary risk according to the EU regulation. 
While not taking a normative stand, the paper offers some interesting policy implications. From the viewpoint of developing supplier countries, as EU foodstuff distributors show growing concerns for food safety, their export opportunities to EU markets are increasingly constrained, the more so, for highvalue, but sanitary risky products. From the viewpoint of the EU importer as well, concentration of imports may be a concern, as it increases the dependence on a few sources, which cannot be totally immune from sanitary risk.

\section{Acknowledgements}

We acknowledge funding by Cepremap and Egide (Programme Germaine de Staël). We would like to thank Anne-Célia Disdier, Lionel Fontagné, Jean Imbs, Thierry Mayer, Marcelo Olarreaga, Mathias Thoenig and two anonymous referees for very helpful comments. Also we give our thanks to participants at the Graduate Seminar in International Economics of the Paris School of Economics, the International Trade Research Conference (December 2009, Fort Myers, FL, USA), the RIEF Conference (June 2010, Kiel, Germany), the Asia-Pacific Trade Seminar (Osaka, June 2010), the 119th EEAE Seminar (Capri, 2010, Italy).

\section{References}

Baylis, K., Nogueira, L. and Pace, K. (2010). Food import refusals: evidence from the European Union. American Journal of Agricultural Economics 93(2): 566-572.

Besedes, T. and Prusa, T. (2006). Ins, outs and the duration of trade. Canadian Journal of Economics 104: 635-654.

Cadot, O., Carrère, C. and Strauss-Kahn, V. (2011). Export diversification: what's behind the hump? Review of Economics and Statistics 93(2): 590-605.

Czubala, W., Shepherd, B. and Wilson, J. S. (2007). Help or hindrance? The impact of harmonized standards on African exports. Policy Research Working Paper Series 4400. The World Bank.

Diaz Rios, L. and Jaffee, S. (2008). Barrier, catalyst, or distraction: standards, competitiveness, and Africa's groundnut exports to Europe. Agriculture and Rural Development Discussion Paper 39. The World Bank.

Disdier, A.-C., Fontagné, L. and Mimouni, M. (2008). The impact of regulations on agricultural trade: evidence from the SPS and TBT agreements. American Journal of Agricultural Economics 90(2): 336-350.

Eaton, J., Eslava, M., Kugler, M. and Tybout, J. (2008). The margins of entry into export markets: evidence from Colombia. In: E. Helpman, D. Marin and T. Verdier (eds), The Organization of Firms in a Global Economy. Cambridge, MA: Harvard University Press.

Evenett, S. and Venables, A. (2002). Export growth in developing countries: market entry and bilateral trade flows. Unpublished manuscript.

Fontagné, L., Mimouni, M. and Pasteels, J. M. (2005). Estimating the impact of environmental SPS and TBT on international trade. Integration and Trade Journal 22: 7-37.

Gallezot, J. (2003). Real access to the EU agricultural market. Unpublished manuscript, INRA-Grignon. 
Garcia Martnez, M., Poole, N. D. and Skinner, C. (2006). Food safety performance in European Union accession countries: benchmarking the fresh produce import sector in Hungary. Agribusiness: An International Journal 22 (1): 69-89.

Helpman, E., Melitz, M. and Rubinstein, Y. (2008). Trading partners and trading volumes. Quarterly Journal of Economics 123(2): 441-487.

Henson, S. and Jaffee, S. (2004). Standards and agro-food exports from developing countries: rebalancing the debate. World Bank Policy Research Paper 3348.

Hummels, D. and Klenow, P. (2005). The variety and quality of a nation's exports. American Economic Review 95(3): 704-723.

Imbs, J. and Wacziarg, R. (2003). The stages of diversification. American Economic Review 93(1): 63-86.

Jaffee, S., van der Meer, K., Henson, S., de Haan, C., Sewadeh, M., Igancio, L., Lamb, J. and Bergovoy Lisazo, M. (2005). Food safety and agricultural health standards: challenges and opportunities for developing country exports. World Bank Poverty Reduction and Economic Management Trade Unit and Agriculture and Rural Development Department Report 31207.

Jaud, M. (2010). Reputations and trade patterns. Food standards, finance and trade: five essays in international trade. Ph.D. thesis, EHESS, Paris, 45-66.

Jaud, M. (2011). The RASFF database, a description. Unpublished manuscript. The World Bank.

Klinger, B. and Lederman, D. (2004). Discovery and development: an empirical exploration of 'new' products. Policy Research Working Paper 3450. The World Bank.

Maskus, K. E., Otsuki, T. and Wilson, J. S. (2005). The cost of compliance with product standards for firms in developing countries: an econometric study. Policy Research Working Paper 3590. The World Bank.

Moenius, J. (2006). The good, the bad and the ambiguous: standards and trade in agricultural products. Unpublished manuscript.

Otsuki, T., Wilson, J. S. and Sewadeh, M. (2001). Saving two in a billion: quantifying the trade effect of European food safety standards on African exports. Food Policy 26: 495-514.

Rauch, J. E. and Watson, J. (2003). Starting small in an unfamiliar environment. International Journal of Industrial Organization 21(7): 1021-1042.

Reardon, T. and Timmer, C. P. (2007). Transformation of markets for agricultural output in developing countries since 1950: how has thinking changed? In: R. Evenson and P. Pingali (eds), Handbook of Agricultural Economics. Amsterdam: NorthHolland Publishing Company, 2807-2855.

Theil, H. (1972). Statistical Decomposition Analysis. Amsterdam: North-Holland Publishing Company. 